\title{
Dynamics of Protein Phosphorylation in Sensory Neurons of Aplysia
}

\author{
R. Homayouni,' J. H. Byrne, ${ }^{2}$, and A. Eskin' \\ ${ }^{1}$ Department of Biochemical and Biophysical Sciences, University of Houston, Houston, Texas 77204-5934, and \\ 2Department of Neurobiology and Anatomy, University of Texas Medical School, Houston, Texas 77225
}

Protein phosphorylation plays important roles in the mechanisms underlying serotonin (5-HT)-induced presynaptic facilitation of Aplysia sensory neurons. To study mechanisms involved in facilitation, we investigated the pattern of protein phosphorylation in sensory neurons as a function of different durations of 5-HT. Two minutes and $1.5 \mathrm{hr}$ treatments with 5-HT altered the phosphorylation of 5 and 10 proteins, respectively. These different duration treatments with 5-HT produced unique effects on the phosphorylation of different sets of proteins. This result suggests that cells may encode and measure the duration of a stimulus by the pattern of specific proteins that are phosphorylated or dephosphorylated. In addition, because the changes in phosphorylation produced by 2 min treatments with 5-HT were not observed after 25 min treatments with 5-HT, mechanisms must exist for the transient phosphorylation of some proteins even when the 5-HT treatment persists. Anisomycin, an inhibitor of protein synthesis, blocked the effect of $1.5 \mathrm{hr}$ treatments with 5-HT on the phosphorylation of six proteins but had no effect on the phosphorylation change of four other proteins. Both CPT-CAMP (an activator of protein kinase A) and PDAC (an activator of protein kinase C) mimicked the effects of 5-HT on four proteins. Interestingly, the effect of 5-HT on these four proteins did not require protein synthesis. CPT-cAMP, but not PDAc, mimicked the effect of 5-HT on one protein (L55) and, the effect of 5-HT on this protein appeared to require protein synthesis. Because both activation of PKA and protein synthesis are involved in the induction of longterm facilitation, protein L55 is a good candidate for a protein that might play a key role in long-term facilitation. Finally, the effects of 5-HT on four proteins were not mimicked by either CPT-cAMP or PDAc. This finding raises the interesting possibility that some effects of 5-HT are mediated by second-messenger systems other than PKA or PKC.

IKey words: serotonin, two-dimensional polyacrylamide gel electrophoresis, facilitation, CAMP, protein kinase C, protein synthesis]

Protein phosphorylation-dephosphorylation is a common mechanism by which extracellular signals alter the activities of intracellular proteins and regulate diverse cellular functions.

\footnotetext{
Received Mar. 8, 1994; revised May 24, 1994; accepted June 23, 1994.

We are grateful to R. E. Zwartjes for helping to establish the labeling techniques used in this study and for his contributions to some of the earlier experiments. We also thank Mr. Z. Chen for his assistance in data analysis. This work was supported by National Institute of Health Grant NS28462 to A.E. and National Institute of Mental Health Award K05 MH00649 to J.B.

Correspondence should be addressed to Arnold Eskin at the above address. Copyright (C) 1995 Society for Neuroscience 0270-6474/95/150429-10\$05.00/0
}

Regulation of protein phosphorylation involves a large number of different components such as second messengers, kinases, and phosphatases. In addition, regulation of protein phosphorylation occurs over a wide spectrum of time. For example, the onset of some changes in phosphorylation occurs seconds after stimulation, while other changes occur minutes or hours after stimulation (Sato et al., 1988; Mooney and Anderson, 1989; Ahn et al., 1990; Donaldson et al., 1991). Moreover, the duration of the changes in phosphorylation may range from a few minutes to several hours (Mooney and Anderson, 1989; Sweatt and Kandel, 1989; Wahl et al., 1989; Hagiwara et al., 1992; Moreland et al., 1992). Thus, elucidation of regulatory mechanisms may require investigation of the dynamics of phosphorylation events in addition to identification of the various components of the phosphorylation system. A field in which the dynamics of phosphorylation appears to play an important role is the study of neuronal plasticities, which may underlie learning and memory (Byrnc ct al., 1993).

The tail-siphon and siphon-gill withdrawal reflexes of the marine mollusc Aplysia californica have been used extensively to study cellular mechanisms underlying learning and memory (reviewed in Byrne et al., 1991; Hawkins et al., 1993). These reflexes exhibit both short-term (lasting minutes) and long-term (lasting hours to days) sensitization, a form of nonassociative learning. Sensitizing stimuli facilitate the synaptic connections between sensory and their follower neurons (Carew et al., 1971; Walters et al., 1983; Frost et al., 1985). Several lines of evidence suggest that these effects are mediated, at least in part, by serotonin (5-HT). Synaptic facilitation of sensorimotor connections requires an intact serotonergic system and can be mimicked by treatments with serotonin of both isolated ganglia and isolated sensory neurons in culture (Brunelli et al., 1976; Walters et al., 1983; Montarolo et al., 1986; Glanzman et al., 1989; Sugita et al, 1992; Pieroni and Byrne, 1992; Emptage and Carew, 1993). Immunohistochemical evidence suggests that sensory neurons receive serotonergic innervation (Kistler et al., 1985; Zhang et al., 1991). Both short-term and long-term effects of 5-HT on sensory neurons appear to be mediated in part through elevation of intracellular cAMP and subsequent activation of cAMP-dependent protein kinase (PKA) (Castellucci et al., 1980, 1982; Bernier et al., 1982; Ocorr and Byrne, 1985; Greenberg et al., 1987; Schacher et al., 1988; Scholz and Byrne, 1988). Moreover, the phosphorylation of a common set of proteins may be involved in both short- and long-term facilitation (Sweatt and Kandel, 1989). However, some short-term but not longterm effects of 5-HT may be mediated by the activation of protein kinase C (PKC) (Sugita et al., 1992). On the other hand, long-duration but not short-duration treatments with 5-HT appear to regulate the phosphorylation and subsequent activation 

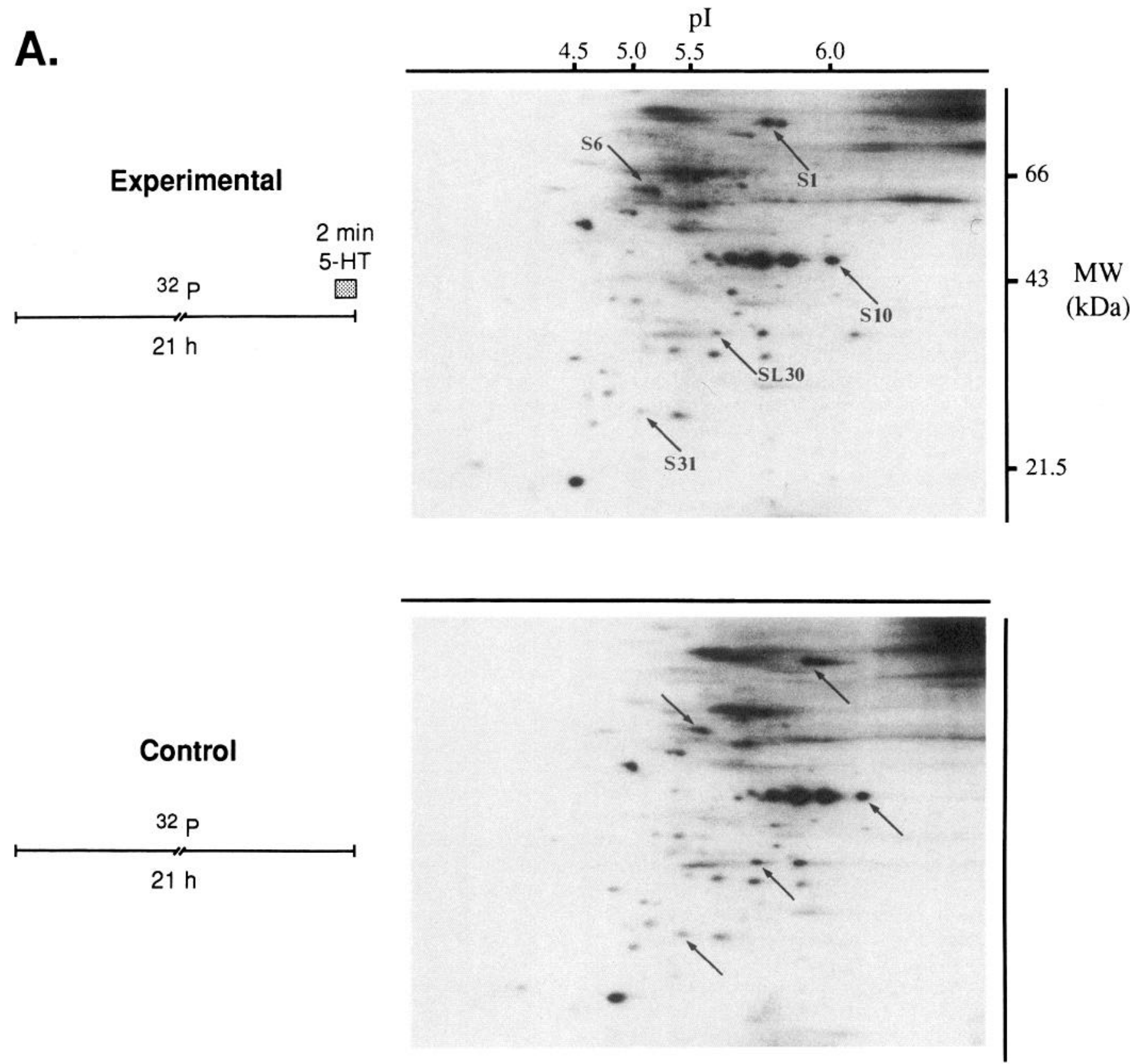

Figure 1. 2-D PAGE autoradiograms of ${ }^{32} \mathrm{P}$-labeled proteins from pleural sensory neurons after treatment of pleural-pedal ganglia with applications of 5-HT lasting $2 \mathrm{~min}(A)$ or $1.5 \mathrm{hr}(B)$. Matched pleural-pedal ganglia were removed from animals and exposed to ${ }^{32} \mathrm{P}$ for $21 \mathrm{hr}$. During the end of the exposure to ${ }^{32} \mathrm{P}$, the experimental ganglia were treated with $5-\mathrm{HT}(5 \mu \mathrm{M})$. At the end of treatments, sensory neurons were removed from pleural ganglia and their proteins extracted for 2-D PAGE analysis. The proteins whose phosphorylation was significantly affected by each duration of 5 -HT are marked by arrow.

of a transcription factor related to the CRE binding protein (CREB) (Dash et al., 1990; Kaang et al., 1993).

To study mechanisms involved in facilitation, we investigated the pattern of protein phosphorylation in Aplysia sensory neurons as a function of different durations of 5-HT. A long-term goal of these studies is to identify proteins whose phosphorylation is regulated by 5-HT. Protein phosphorylation has been investigated in Aplysia, but only a few phosphoproteins have been identified (Lemos et al., 1984; Saitoh and Schwartz, 1985; Sweatt and Kandel, 1989; Zwartjes and Eskin, 1990; Azhderian and Kaczmarek, 1991).

\section{Materials and Methods}

Treatment of pleural-pedal ganglia and preparation of samples for electrophoresis. Aplysia californica were obtained from Alacrity Marine Biological (Redondo Beach) and Marinus Inc. (Long Beach) and were maintained in artificial seawater (Instant Ocean) at $15^{\circ} \mathrm{C}$ for at least 3 $\mathrm{d}$ before use. The animals were anesthetized by injection of an amount of isotonic $\mathrm{MgCl}_{2}$ equal to approximately one-half of their body weight. For each experiment, pleural-pedal ganglia were isolated from six animals and placed in dishes containing $50 \%$ isotonic $\mathrm{MgCl}_{2}$ and $50 \%$ buffered filtered seawater (BFSW; seawater containing $30 \mathrm{~mm}$ HEPES, $100 \mu \mathrm{g} / \mathrm{ml}$ streptomycin, $100 \mathrm{U} / \mathrm{ml}$ penicillin-G, pH 7.65) at $15^{\circ} \mathrm{C}$. The right and left ganglia were alternately placed into experimental and 


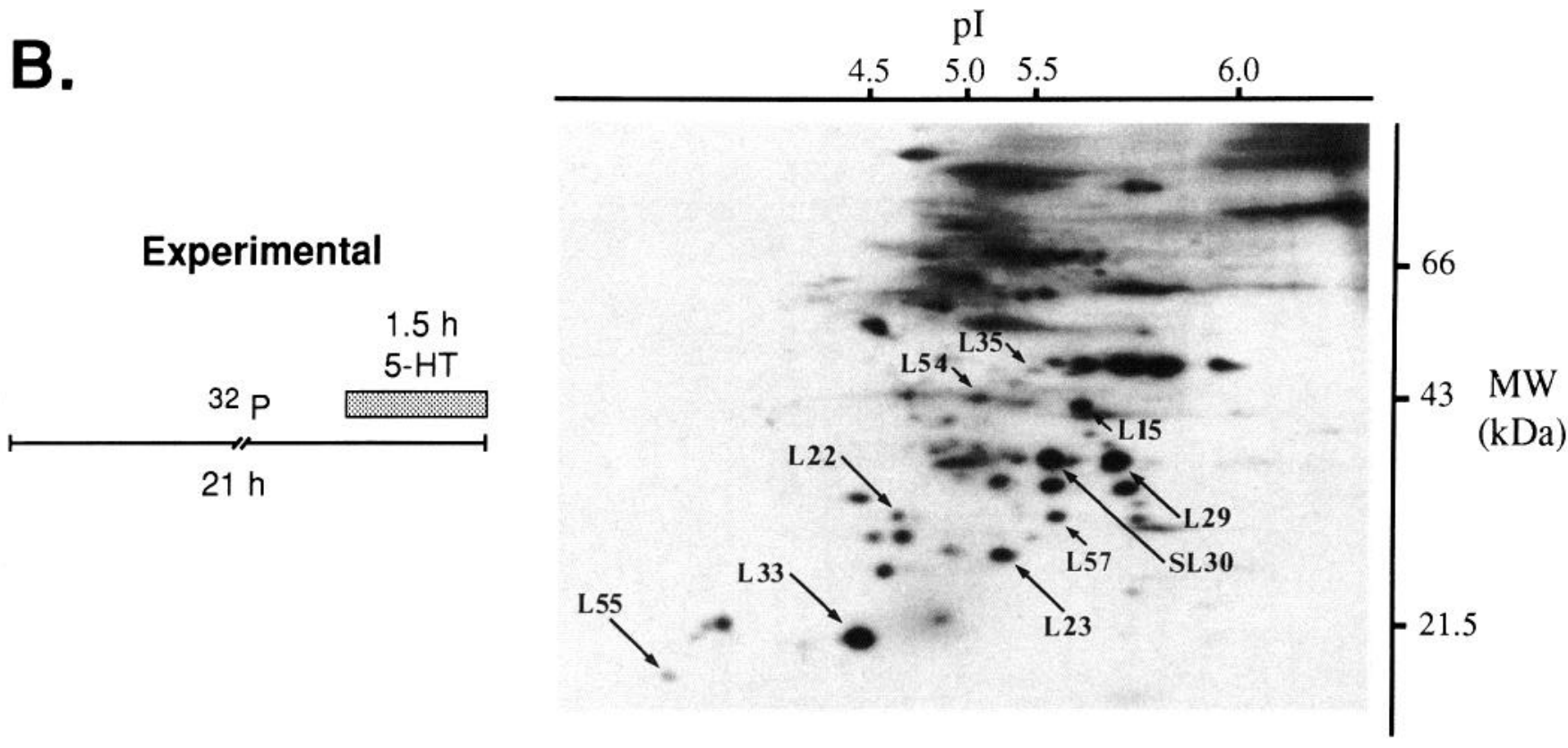

Control
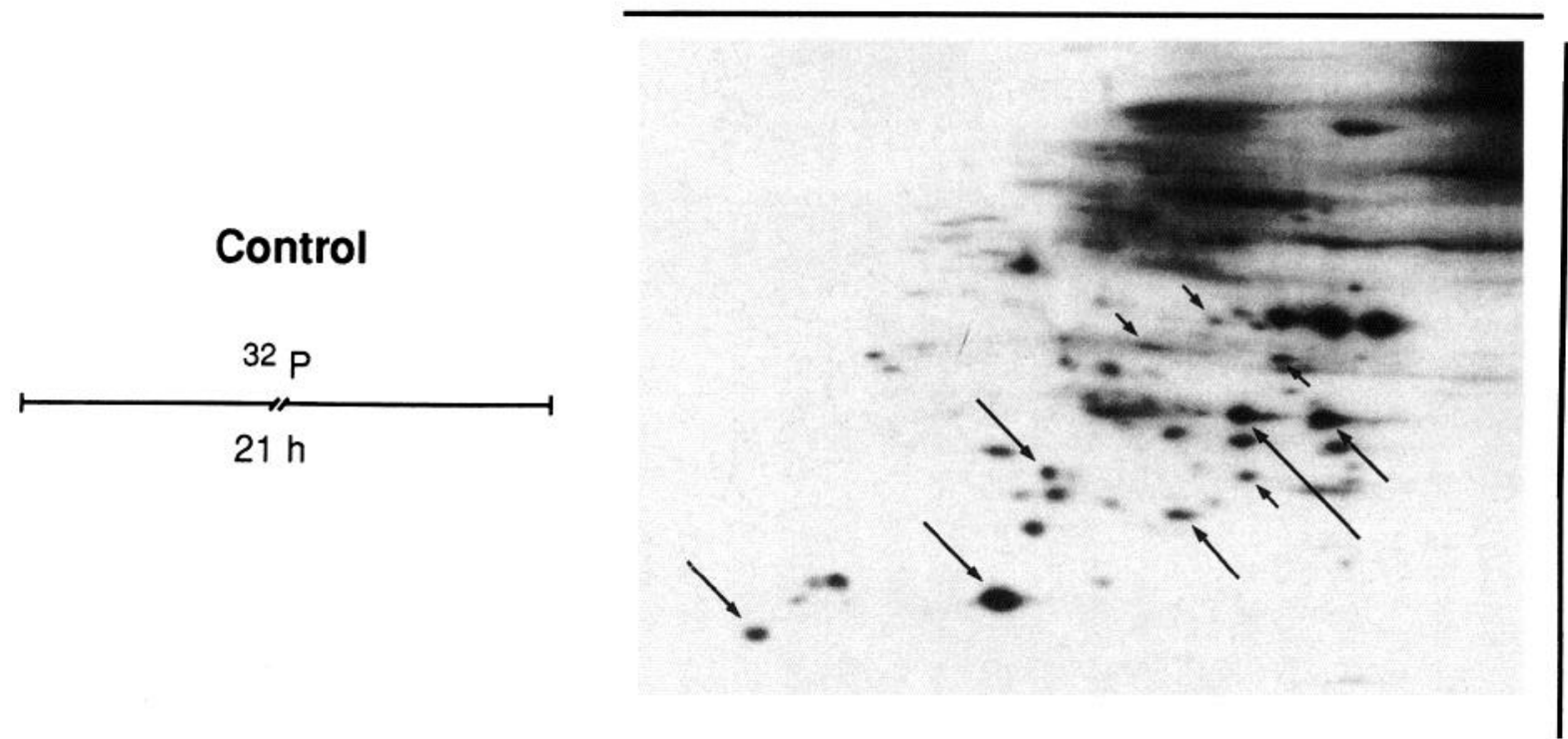

Figure 1. Continued.

control chambers. After $2 \mathrm{hr}$, the ganglia were exposed to labeling solution containing BFSW without sulfates or phosphates $\left(10 \mathrm{~mm} \mathrm{CaCl}_{2}\right.$, $10 \mathrm{~mm} \mathrm{KCl}, 50 \mathrm{~mm} \mathrm{MgCl}, 440 \mathrm{~mm} \mathrm{NaCl}, 100 \mu \mathrm{g} / \mathrm{ml}$ streptomycin, $100 \mathrm{U} / \mathrm{ml}$ penicillin-G, $30 \mathrm{~mm}$ HEPES $\mathrm{pH} 7.65$ ) and ${ }^{32} \mathrm{P}$-orthophosphoric acid $(0.2 \mathrm{mCi} / \mathrm{ml})$ for $21 \mathrm{hr}$ (Bernier et al., 1982; Sweatt and Kandel, 1989; Zwartjes and Eskin, 1989). During the end of the labeling period, the experimental group of six ganglia was treated with either serotonin (5-hydroxytryptamine hydrochloride, Sigma), anisomycin (Sigma), or 5-HT plus anisomycin. In another series of experiments, experimental ganglia were treated with phorbol diacetate (PDAc, Sigma) or 8-4-chlorophenylthio-cAMP (CPT-cAMP, Sigma). Experimental treatments were introduced by adding concentrated solutions to the bathing medium followed by swirling of both control and experimental chambers to mix the solutions.

At the end of experimental treatments, the ganglia were frozen with liquid nitrogen and stored at $-80^{\circ} \mathrm{C}$. Clusters of sensory neurons were removed from ganglia while frozen in $50 \% \mathrm{BFSW}, 50 \%$ propylene glycol solution (Noel et al., 1991). After removal, clusters of sensory neurons were placed in $50 \mu \mathrm{l}$ of solubilization buffer $(9.1 \mathrm{M}$ urea, $5 \% \mathrm{v} / \mathrm{v}$ ampholytes, $5 \% \mathrm{w} / \mathrm{v}$ 2-mercaptoethanol, 3\% w/v 3-[(3-cholamidopropyl)dimethylammonio]-1-propanesulfonate(CHAPS), $50 \mathrm{~mm}$ Tris base, $5 \mathrm{~mm}$ EDTA, $1 \mathrm{~mm}$ EGTA, $0.125 \mathrm{mg} / \mathrm{ml}$ bacitracin, $0.125 \mathrm{mg} / \mathrm{ml}$ trypsin inhibitor, $1.5 \mathrm{mg} / \mathrm{ml}$ benzamidine, $0.19 \mathrm{IU} / \mathrm{ml}$ aprotinin, 40 mм sodium pyrophosphate, and $100 \mathrm{~mm}$ sodium fluoride). The incorporation of ${ }^{32} \mathrm{P}$ into proteins for a given sample was estimated by measuring ${ }^{32} \mathrm{P}$ of trichloroacetic acid (TCA) precipitable proteins (Yeung and Eskin, 1987).

Two-dimensional polyacrylamide gel electrophoresis (2-D PAGE). The proteins in samples of sensory neurons were separated by 2-D PAGE using procedures similar to O'Farrell (1975) and reported by Yeung and Eskin (1987) and Eskin et al. (1989). Proteins were first separated in a pH gradient of 4-7, established with a mixture of ampholytes (Phar- 
Table 1. Percentage change in phosphorylation of sensory neuron proteins produced by various 5-HT treatments

\begin{tabular}{|c|c|c|c|c|c|c|}
\hline $\begin{array}{l}\text { Protein } \\
\text { number }\end{array}$ & $\begin{array}{l}\mathrm{MW} \\
(\mathrm{kDa})\end{array}$ & $\mathrm{pI}$ & $\begin{array}{l}2 \text { min } 5-\mathrm{HT} \\
\text { treatment }^{a}\end{array}$ & $\begin{array}{l}1.5 \mathrm{hr} 5-\mathrm{HT} \\
\text { treatment }\end{array}$ & $\begin{array}{l}2 \text { min } 5-\mathrm{HT} \\
\text { treatment } \\
\text { (examined } 1.5 \\
\text { hr later) }\end{array}$ & $\begin{array}{l}25 \min 5-\mathrm{HT} \\
\text { treatment }\end{array}$ \\
\hline \multicolumn{7}{|c|}{ Proteins affected by $2 \min 5-\mathrm{HT}$} \\
\hline S1 & 83.1 & 5.82 & $32 \pm 8(9)^{* *}$ & $6 \pm 16(9)$ & $-8 \pm 7$ & $3 \pm 17(10)$ \\
\hline S6 & 63.7 & 5.23 & $24 \pm 6(9)^{* *}$ & $-8 \pm 14(9)$ & $18 \pm 22(8)$ & $7 \pm 8 \quad(10)$ \\
\hline $\mathrm{S} 10$ & 46.7 & 6.00 & $51 \pm 18(9)^{*}$ & $2 \pm 18(7)$ & $-15 \pm 8$ & $7 \pm 18(9)$ \\
\hline S31 & 26.1 & 5.05 & $-22 \pm 6(10)^{* *}$ & $-1 \pm 7(10)$ & $19 \pm 10(9)$ & $-4 \pm 10(10)$ \\
\hline \multicolumn{7}{|c|}{ Proteins affected by both $2 \mathrm{~min}$ and $1.5 \mathrm{hr} 5-\mathrm{HT}$} \\
\hline SL30 & 35.2 & 5.60 & $-16 \pm 6(10)^{*}$ & $25 \pm 10(10)^{*}$ & $1 \pm 9$ & $4 \pm 19(10)$ \\
\hline \multicolumn{7}{|c|}{ Proteins affected by $1.5 \mathrm{hr} 5-\mathrm{HT}$} \\
\hline $\mathrm{L} 15$ & 41.2 & 5.70 & $20 \pm 8 \quad(10)$ & $77 \pm 23(9)^{*}$ & $-14 \pm 5(9)^{*}$ & $68 \pm 25(8)^{*}$ \\
\hline L22 & 29.1 & 4.74 & $7 \pm 17(10)$ & $50 \pm 21(10)^{*}$ & $24 \pm 14(9)$ & $135 \pm 37(10)^{* *}$ \\
\hline L23 & 25.2 & 5.36 & $-4 \pm 5 \quad(10)$ & $29 \pm 10(10)^{*}$ & $10 \pm 5$ & $-2 \pm 7 \quad(10)$ \\
\hline L29 & 35.2 & 5.74 & $5 \pm 8 \quad(10)$ & $20 \pm 9(10)^{*}$ & $-6 \pm 6$ & $-4 \pm 8$ \\
\hline L33 & 19.8 & 4.50 & $0 \pm 6 \quad(10)$ & $-14 \pm 5(10)^{*}$ & $6 \pm 5$ (9) & $3 \pm 7$ (10) \\
\hline L35 & 46.7 & 5.54 & $2 \pm 15(9)$ & $33 \pm 9(8)^{*}$ & $-12 \pm 7$ & $-3 \pm 6 \quad(10)$ \\
\hline L54 & 45.5 & 5.29 & $9 \pm 12(10)$ & $23 \pm 7(10)^{* *}$ & $2 \pm 9$ & $-3 \pm 13(9)$ \\
\hline L55 & 18.4 & 3.86 & $-5 \pm 11(8)$ & $-28 \pm 9(10)^{*}$ & $20 \pm 11(5)$ & $8 \pm 14(10)$ \\
\hline $\mathrm{L} 57$ & 29.5 & 5.62 & $5 \pm 14(9)$ & $46 \pm 14(9)^{* *}$ & $3 \pm 8$ & $-5 \pm 6 \quad(10)$ \\
\hline
\end{tabular}

${ }^{a}$ Mean percentage change \pm SE. The percentage change was calculated by (ODe - ODc)/ODc $\times 100$. The number of experiments appears in parentheses. In some experiments, it was not possible to obtain quantitative data for specific proteins because, for example, the protein did not focus well or the background surrounding the protein was very high. A two tailed $t$ test was performed to determine whether the difference between the OD of an experimental and control protein was significant.

${ }^{*} p<0.05$.

$* * p<0.01$.

macia), and then by a $12 \%$ polyacrylamide SDS slab gel (Minislab gels; Idea Scientific, Corvallis, OR). Equal amounts of radioactivity from experimental and control samples were loaded onto separate isoelectric focusing gels. Experimental and control samples from an experiment were always run together on the same batch of isoelectric and slab gels. After fixation with 50\% trichloroacetic acid, the gels were dried and exposed to film (Kodak XAR) at room temperature. The same gels were exposed to films for different durations to insure that the film was in the linear range of sensitivity.

The molecular weights (MW) and isoelectric points (pI) of proteins were determined by running 2-D SDS-PAGE standards (Bio Rad) along with samples of proteins from sensory neurons. After electrophoresis, the gels were stained with Coomassie Brilliant Blue R-250 (Bio Rad) and the pIs and MWs of the phosphoproteins were estimated by interpolation.

Analysis of autoradiograms. Autoradiograms were scanned using a computerized image analysis system (DNA Proscan Inc., Nashville, TN) and the integrated optical densities (ODs) of protein spots were automatically determined. The changes in ODs of control and experimental spots were confirmed by visual analysis. Large inconsistencies between the automated analysis and visual analysis were further examined and resolved. The ODs of proteins from each gel were normalized for any discrepancies in the amount of radioactivity loaded on experimental and control gels by calculating a percentage OD. The percentage OD of a protein was computed by dividing its OD with the sum of the ODs of a subset of proteins in a given gel. This subset consisted of about 30 proteins that were reliably analyzed by the computer in all experiments, located at various locations of the gel, and spanned a range of ODs. Although this subset of proteins contained a few proteins that were affected by various experimental treatments, the overall sums of the ODs for the experimental proteins were not different from the overall sums of the ODs of the control proteins. For example, the mean ratio of the sum of experimental protein ODs to sum of the control protein ODs for $1.5 \mathrm{hr} 5$-HT experiments was $1.01 \pm 0.06$. A two-tailed $t$ test was performed to determine whether the difference between the OD of an experimental (ODe) and control (ODc) protein was statistically significant.

\section{Results}

Changes in protein phosphorylation by 2 min and $1.5 \mathrm{hr}$ treatments with 5-HT

Treatment of sensory neurons with 5-HT for 1 to 5 min produces synaptic facilitation lasting a few minutes, and treatment with 5 -HT over $1.5 \mathrm{hr}$ produces facilitation lasting $24 \mathrm{hr}$ (Brunelli et al., 1976; Montarolo et al., 1986; Rayport and Schacher, 1986; Emptage and Carew, 1993). To investigate the phosphorylation events related to synaptic facilitation, we examined the changes in phosphorylation of sensory neuron proteins after exposure of pleural-pedal ganglia to $2 \mathrm{~min}$ and $1.5 \mathrm{hr}$ treatments with 5 -HT $(5 \mu \mathrm{M})$. The incorporation of ${ }^{32} \mathrm{P}$ into proteins was measured by analyzing autoradiograms of two-dimensional polyacrylamide gels. Approximately 65 phosphoproteins could be studied reliably in these gels (Fig. 1). Since phosphorylation of a protein affects its charge and, consequently, its $\mathrm{pI}$, it is possible that some proteins on our gels, which have similar MWs but different pIs, are charge isomers of the same protein.

The phosphorylation of 14 proteins was affected by the $2 \mathrm{~min}$ and $1.5 \mathrm{hr}$ treatments with 5-HT (Table 1). Notably, the phosphorylation of protcins was dccreased as well as increased by 5-HT. The phosphorylation of three proteins (S1, S6, and S10) was increased and two proteins (S31 and SL30) was decreased by 2 min treatments with 5-HT (Fig. 1A). The phosphorylation of eight proteins (L15, L22, L23, L29, SL30, L35, L54, and L57) was increased and two proteins (L33 and L55) was decreased by $1.5 \mathrm{hr}$ treatments with 5 -HT (Fig. $1 B$ ). Only one protein (SL30) was affected by both durations of 5-HT (Table 1). However, the phosphorylation of SL30 was decreased by the $2 \mathrm{~min}$ 
treatment with $5-\mathrm{HT}$ but it was increased by the $1.5 \mathrm{hr}$ treatment with $5-\mathrm{HT}$. Therefore, $2 \mathrm{~min}$ and $1.5 \mathrm{hr}$ treatments with 5-HT did not appear to have the same effect on any one protein.

Time and duration dependence of 5-HT effects on protein phosphorylation

The observation that $2 \mathrm{~min}$ and $1.5 \mathrm{hr}$ treatments with $5-\mathrm{HT}$ had different effects on proteins raised two issues. First, do the changes produced by 2 min treatments with 5 -HT persist or decay $1.5 \mathrm{hr}$ after the brief treatment with 5-HT? Second, are the phosphorylation changes produced by a $1.5 \mathrm{hr}$ treatment with 5-HT a function of the duration of 5-HT treatment or a function of the time after some minimal treatment with 5-HT? To address these issues, we examined changes in protein phosphorylation $1.5 \mathrm{hr}$ after a 2 min treatment with $5-\mathrm{HT}$.

None of the changes in phosphorylation that were produced at the end of $2 \mathrm{~min}$ or $1.5 \mathrm{hr}$ treatments with 5 -HT occurred $1.5 \mathrm{hr}$ after a single $2 \mathrm{~min}$ pulse of 5-HT (Table 1). The change in phosphorylation of the five proteins (S1, S6, S10, SL30, and S31) produced immediately after a 2 min treatment with $5-\mathrm{HT}$ appeared to decay within $1.5 \mathrm{hr}$ after the removal of 5-HT. Furthermore, the change in phosphorylation of the 10 proteins observed after $1.5 \mathrm{hr}$ treatment with 5 -HT did not occur $1.5 \mathrm{hr}$ after a 2 min treatment with 5-IIT. IIowever, the phosphorylation of one protein (L15) was significantly changed $1.5 \mathrm{hr}$ after a 2 min treatment with $5-\mathrm{HT}$, albeit in a different direction than the change observed after $1.5 \mathrm{hr}$ treatment with 5 -HT (Table 1).

The above results indicate that the phosphorylation changes produced by 2 min treatments with 5-HT are transient and those phosphorylation changes produced by $1.5 \mathrm{hr}$ treatments with 5-HT require long duration treatments to occur. To investigate further the transient nature of the short duration effects and the duration dependence of the long duration effects, we examined protein phosphorylation at the end of 25 min treatments with 5-HT (Table 1). None of the changes in phosphorylation produced by 2 min treatments with 5 -HT were evident at the end of 25 min treatments (Fig. $2 A$ ). Therefore, even though $5-\mathrm{HT}$ continues to be present, the phosphorylation changes apparent after 2 min treatments with 5 -HT seemed to disappcar at somc time during the 25 min treatment with $5-\mathrm{HT}$. Also, the change in the phosphorylation of eight proteins affected by $1.5 \mathrm{hr}$ treatments with 5-HT was not apparent after 25 min treatments with 5-HT (Fig. 2B). Therefore, the changes in phosphorylation of these proteins appeared to require either longer durations of 5-HT than $25 \mathrm{~min}$ or longer periods of time after 25 min treatments with 5-HT. The phosphorylation of only two proteins (L15 and L22) was affected similarly by both $25 \mathrm{~min}$ and 1.5 hr treatments with 5-HT (Fig. 2C). Parenthetically, there appeared to be several proteins whose phosphorylation was affected only by $25 \mathrm{~min}$ treatments with 5 -HT and not by the 2 min or $1.5 \mathrm{hr}$ treatments with 5-HT (data not shown).

Effect of anisomycin on the phosphorylation changes produced by 1.5 hr treatments with $5-H T$

Serotonin treatments of $1.5 \mathrm{hr}$ modify the synthesis of proteins (Barzilai et al., 1989; Noel et al., 1991, 1993). Thus, it is possible that the changes we observed in phosphorylation of proteins were due to an effect of 5-HT on protein synthesis. Also, inhibition of protein synthesis during treatment with 5-HT blocks the appearance of long-term facilitation (Montarolo et al., 1986). Therefore, we investigated the effect of inhibition of protein
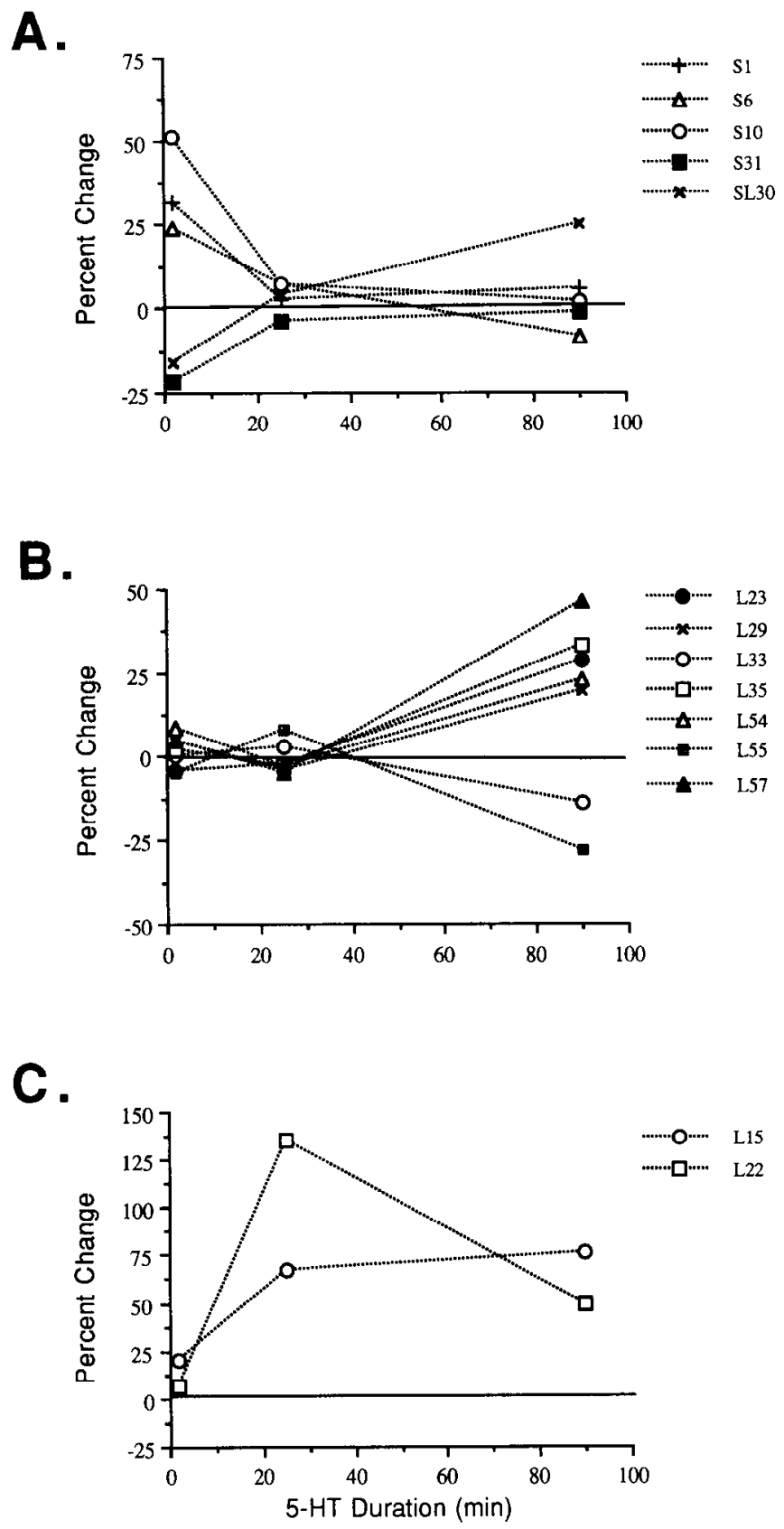

Figure 2. Comparison of the percentage changes in the phosphorylation of specific proteins produced by $2 \mathrm{~min}, 25 \mathrm{~min}$, and $1.5 \mathrm{hr}$ treatments with $5-\mathrm{HT}$. Data for this figure were taken from Table 1 . The phosphorylation of some proteins was affected transiently by $2 \mathrm{~min}$ treatments with 5-HT $(A)$. Another set of proteins was only changed by the long, $1.5 \mathrm{hr}$ treatment with 5-HT $(B)$. The phosphorylation of L15 and L22 was affected by both $25 \mathrm{~min}$ and $1.5 \mathrm{hr}$ treatments with 5-HT but not by the 2 min treatments with 5 -HT $(C)$.

synthesis by anisomycin $(10 \mu \mathrm{M})$ on proteins whose phosphorylation appeared to be affected by $1.5 \mathrm{hr}$ treatments with $5-\mathrm{HT}$. Anisomycin reversibly inhibits protein synthesis in cultured sensory neurons as well as other Aplysia tissues (Schwartz et al., 1971; Eskin et al., 1984; Montarolo et al., 1986). As a control, we first examined the effect of anisomycin by itself on phosphorylation of sensory neuron proteins. The phosphorylation of only one protein (L22) was significantly altered by anisomycin treatments (Table 2). We next studied whether the phosphor- 


\begin{tabular}{|c|c|c|c|c|c|}
\hline Protein & $\begin{array}{l}\text { MW } \\
(\mathrm{kDa})\end{array}$ & $\mathrm{pI}$ & $\begin{array}{l}1.5 \mathrm{hr} 5-\mathrm{HT} \\
\text { treatment }{ }^{a}\end{array}$ & $\begin{array}{l}2.5 \mathrm{hr} \text { anisomycin } \\
\text { treatment }\end{array}$ & $\begin{array}{l}\text { Aniso }+5 \mathrm{HT} \\
\text { treatment }\end{array}$ \\
\hline SL30 & 35.2 & 5.60 & $25 \pm 10(10)^{*}$ & $8 \pm 29(8)$ & $7 \pm 11(11)$ \\
\hline L15 & 41.2 & 5.70 & $77 \pm 23(9)^{*}$ & $24 \pm 16(9)$ & $72 \pm 19(11)^{* *}$ \\
\hline $\mathrm{L} 22$ & 29.1 & 4.74 & $50 \pm 21(10)^{*}$ & $-28 \pm 7(9)^{*}$ & $63 \pm 20(11)^{*}$ \\
\hline L23 & 25.2 & 5.36 & $29 \pm 10(10)^{*}$ & $3 \pm 6 \quad(9)$ & $27 \pm 10(11)^{*}$ \\
\hline L29 & 35.2 & 5.74 & $20 \pm 9(10)^{*}$ & $9 \pm 19(9)$ & $-1 \pm 6$ \\
\hline L33 & 19.8 & 4.50 & $-14 \pm 5(10)^{*}$ & $-3 \pm 6$ & $-29 \pm 7(11)^{* *}$ \\
\hline L35 & 46.7 & 5.54 & $33 \pm 9(8)^{*}$ & $-8 \pm 10(7)$ & $-1 \pm 12(10)$ \\
\hline L54 & 45.4 & 5.29 & $23 \pm 7(10)^{* *}$ & $14 \pm 9$ & $7 \pm 20(9)$ \\
\hline L55 & 18.4 & 3.86 & $-28 \pm 9(10)^{*}$ & $2 \pm 17(9)$ & $15 \pm 11(10)$ \\
\hline L57 & 29.5 & 5.62 & $46 \pm 14(9)^{* *}$ & $1 \pm 24(6)$ & $29 \pm 32(11)$ \\
\hline
\end{tabular}

"Same data as Table 1.

ylation changes produced by $1.5 \mathrm{hr}$ treatments with 5 -HT could be blocked by anisomycin. The effect of $1.5 \mathrm{hr}$ treatment with 5-HT on the phosphorylation of six proteins (SL30, L29, L35, L54, L55, and L57) appeared to be blocked by anisomycin. Anisomycin did not appear to block the effect of 5-HT on four proteins (L15, L22, L23, and L33) since similar changes in phosphorylation were produced by $1.5 \mathrm{hr}$ treatments with 5-HT and $1.5 \mathrm{hr}$ treatments with 5-HT plus anisomycin (Table 2 and Fig. 3A).

\section{Effects of different second messengers on phosphorylation of proteins}

Serotonin activates both PKA and PKC in Aplysia sensory neurons (Castellucci et al., 1980, 1982; Greenberg et al., 1987; Schacher et al., 1988; Sacktor and Schwartz, 1990; Ghirardi et al., 1992; Sossin and Schwartz, 1992; Sugita et al., 1992). To characterize further the proteins whose phosphorylation was altered by $1.5 \mathrm{hr}$ treatments with 5 -HT in this study, we investigated the effects on phosphorylation of activation of PKA using chlorophenylthio cAMP (CPT-cAMP, $1 \mathrm{mM}$ ) and activation of $\mathrm{PKC}$ using phorbol diacetate (PD-Ac, $3 \mu \mathrm{M}$ ). Treatments with CPT-cAMP or PDAc mimic certain effects produced by 5-HT on Aplysia sensory neurons (Greenberg et al., 1987; Baxter and Byrne, 1989; Noel et al., 1991; Critz and Byrne, 1992; Sugita et al., 1992).
Treatments with either $1.5 \mathrm{hr}$ CPT-cAMP or $1.5 \mathrm{hr}$ PDAc affected the phosphorylation of 20 proteins. The effects of treatments with CPT-cAMP and PDAc are shown only for the 10 proteins that were affected by $1.5 \mathrm{hr}$ treatments with 5-HT (Table 3). Treatments with CPT-cAMP and PDAc mimicked the effects of $1.5 \mathrm{hr}$ treatments with 5-HT on the phosphorylation of only four of these proteins (L15, L22, L23, and L33) (Fig. 3A). However, the magnitudes of the changes produced by CPT-cAMP and PDAc were markedly larger than the changes produced by $1.5 \mathrm{hr}$ treatments with 5 -HT (Table 3 ). Treatments with CPT-cAMP, but not PDAc, mimicked the effect of 5-HT on the phosphorylation of L55 (Fig. $3 A$ ). The change in phosphorylation produced by $5-\mathrm{H} \mathrm{T}$ on the remaining five proteins (SL30, L29, L35, L54, and L57) did not appear to be mimicked by cither CPT-cAMP or PDAc. However, CPT-cAMP and PDAc had significant effects on some of these proteins (L29, L35, L54, and L57) but in no case were the directions of these effects produced by 5-HT mimicked by CPT-cAMP or PDAc.

\section{Discussion}

We have shown that different durations of treatments with 5-HT produced unique effects on the phosphorylation of different sets of proteins in Aplysia sensory neurons (Figs. 2,3). This indicates that different biochemical processes are recruited by $2 \mathrm{~min}$ and

\begin{tabular}{|c|c|c|c|c|c|}
\hline Protein & $\begin{array}{l}\mathrm{MW} \\
(\mathrm{kDa})\end{array}$ & $\mathrm{pI}$ & $\begin{array}{l}1.5 \mathrm{hr} 5-\mathrm{HT} \\
\text { treatment }\end{array}$ & $\begin{array}{l}1.5 \mathrm{hr} \text { CPT-cAMP } \\
\text { treatment }\end{array}$ & $\begin{array}{l}1.5 \mathrm{hr} \text { PDAc } \\
\text { treatment }\end{array}$ \\
\hline $\mathrm{L} 15$ & 41.2 & 5.70 & $77 \pm 23(9)^{*}$ & $84 \pm 16(8)^{* *}$ & $207 \pm 38(7)^{* *}$ \\
\hline L22 & 29.1 & 4.74 & $50 \pm 21(10)^{*}$ & $316 \pm 111(8)^{* *}$ & $75 \pm 25(7)^{*}$ \\
\hline L23 & 25.2 & 5.36 & $29 \pm 10(10)^{*}$ & $49 \pm 10(8)^{* *}$ & $132 \pm 9(7)^{* *}$ \\
\hline L33 & 19.8 & 4.50 & $-14 \pm 5(10)^{*}$ & $-41 \pm 5 \quad(7)^{* *}$ & $-77 \pm 2(7)^{* *}$ \\
\hline L55 & 18.4 & 3.86 & $-28 \pm 9(10)^{*}$ & $-29 \pm 8 \quad(7)^{*}$ & $-9 \pm 8 \quad(7)$ \\
\hline L29 & 35.2 & 5.74 & $20 \pm 9(10)^{*}$ & $-18 \pm 12$ & $-14 \pm 9$ \\
\hline SL30 & 35.2 & 5.60 & $25 \pm 10(10)^{*}$ & $-5 \pm 37$ & $-16 \pm 9$ \\
\hline L35 & 46.7 & 5.54 & $33 \pm 9(8)^{*}$ & $-19 \pm 4 \quad(8)^{* *}$ & $-19 \pm 12(6)$ \\
\hline L54 & 45.4 & 5.29 & $23 \pm 7(10)^{* *}$ & $-24 \pm 7 \quad(7)^{*}$ & $-32 \pm 5 \quad(5)^{* *}$ \\
\hline L57 & 29.5 & 5.62 & $46 \pm 14(9)^{* *}$ & $-20 \pm 19$ & $-21 \pm 11(6)$ \\
\hline
\end{tabular}

"Same data as Table 1. 
$1.5 \mathrm{hr}$ durations of treatments with 5-HT. In addition, since the changes in protein phosphorylation produced by 2 min treatments with 5-HT were not observed after $25 \mathrm{~min}$ or $1.5 \mathrm{hr}$ treatments with 5-HT (Fig. 2), mechanisms must exist for the transient phosphorylation of these proteins even when the 5-HT application persists. Our finding that different durations of 5-HT affected the phosphorylation of different sets of proteins suggests that cells may measure the duration of a stimulus by detecting the pattern of which proteins are phosphorylated or dephosphorylated.

In Aplysia neurons, brief application of 5-HT produces shortterm facilitation, whereas application of 5-HT over a $1.5 \mathrm{hr}$ period produces long-term facilitation. The phosphoproteins affected by the different durations of 5-HT may be associated with the different cellular mechanisms underlying short- and long-term facilitation. One case in which a phosphorylation event may be important in induction of long-term but not shortterm facilitation is the activation of a transcription factor closely related to CREB (Dash et al., 1990). Only prolonged treatment with 5-HT stimulates CRE-mediated transcription in Aplysia sensory neurons (Kaang et al., 1993).

The phosphorylation of five proteins was altered by $2 \mathrm{~min}$ treatments with 5-HT, and these alterations decayed within 1.5 hr after the brief 2 min treatment with 5-HT and were not evident after 25 min treatments with 5-HT (Table 2 and Fig. $2 A$ ). Since the duration of short-term facilitation produced by brief treatments with 5-HT persists for only a few minutes (Brunelli et al., 1976), these five proteins could be involved in shortterm facilitation. Previously, Sweatt and Kandel (1989) examined the phosphorylation of proteins immediately after a $2 \mathrm{~min}$ application of 5-HT to isolated clusters of sensory neurons and found a number of proteins whose phosphorylation was altered. However, these proteins could not be found on our 2-D gels based on their relative locations to one another or their MWs and pIs. Although direct comparisons of the results from the Sweatt study with ours is difficult, there are at least two differences in the findings between the two studies. We found a smaller number of proteins (five) affected by the 5-HT treatments than did Sweatt and Kandel (who found 17 proteins, some of which may correspond to charge variants of the same proteins). In addition, Sweatt and Kandel did not report any decreases in the phosphorylation of proteins, whereas we found two significant decreases produced by 5-HT. Differences in the results of these two studies may be due to a number of differences in the methodologies used in these two studies. For example, the techniques used in these studies to separate proteins were rather different. Also, the study by Sweatt and Kandel involved treatments to isolated clusters of sensory neurons, whereas our study involved treatments to isolated ganglia and then removal of sensory neurons for analysis. Although the pleural sensory neurons receive rich serotonergic innervation and have receptors for 5-HT on their somata, it is possible that some of the differences between these studies could be due to activation of cells presynaptic to the sensory neurons when 5-HT was administered to the intact ganglia (Kistler et al., 1985; Montarolo et al., 1986; Ocorr and Byrne, 1986; Glanzman et al., 1989; Zhang et al., 1991).

The phosphorylation of 10 proteins was altered after continuous application of 5-HT for $1.5 \mathrm{hr}$ (Fig. 3A). None of these changes were evident $1.5 \mathrm{hr}$ after a 2 min treatment with 5-HT (Table 2). However, two of these changes were produced after a 25 min treatment with 5-HT (Fig. $2 C$ ). The phosphorylation changes in the proteins requiring long durations of treatments
A.

\begin{tabular}{|c|c|c|c|c|c|c|c|c|c|c|}
\hline protein \# & L15 & L22 & L23 & L33 & L55 & SL30 & L29 & L57 & L35 & L54 \\
\hline $\begin{array}{c}\text { MW (kDa) } \\
\text { PI }\end{array}$ & $\begin{array}{l}41.2 \\
5.70\end{array}$ & 29.1 & 25.2 & 19.8 & 18.4 & 35.2 & 35.2 & 29.5 & 46.7 & 45.4 \\
\hline $\mathbf{1 . 5}$ h 5-HT & + & + & + & - & - & + & + & + & + & + \\
\hline $\begin{array}{c}\text { 1.5h } \\
\text { CPT-cAMP }\end{array}$ & + & + & + & - & - & & & & - & - \\
\hline $\begin{array}{c}\mathbf{1 . 5} \text { h } \\
\text { PDAc }\end{array}$ & + & + & + & - & & & & & & - \\
\hline $\begin{array}{c}\text { Blocked by } \\
\text { anisomycin? }\end{array}$ & & & & & yes & yes & yes & yes & yes & yes \\
\hline
\end{tabular}

B.

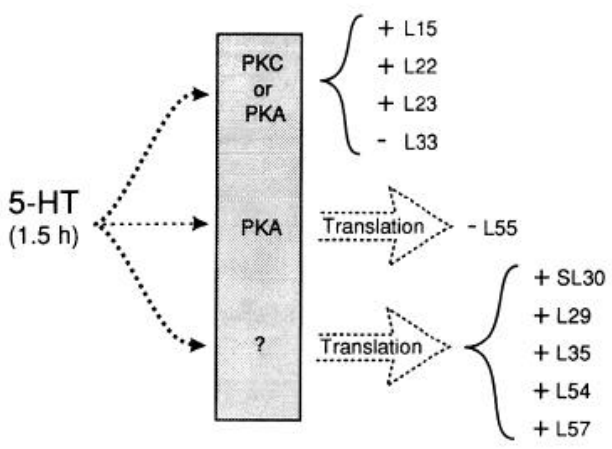

Figure 3. Summary of the effects of $1.5 \mathrm{hr}$ treatments with 5-HT on the phosphorylation of sensory neuron proteins $(A)$ and a model summarizing the possible mechanisms that may be involved in the phosphorylation changes produced by $1.5 \mathrm{hr}$ treatments with $5-\mathrm{HT}(B) . A$, Combined results from Tables 1,2 , and 3 in which "+" indicates a significant increase in phosphorylation and "-" indicates a significant decrease in phosphorylation. A blank space indicates that the treatment had no significant effect on phosphorylation. The shaded areas highlight the changes in the phosphorylation of proteins produced by CPT-cAMP or PDAc treatments that are similar to those changes produced by 1.5 hr treatments with 5-HT. $B$, The effects of various treatments on the proteins whose phosphorylation was altered by $1.5 \mathrm{hr}$ treatments with 5 -HT fall into three categories. The change in the phosphorylation produced by 5 -HT of one group of proteins $(L 15, L 22, L 23$, and L33) may be mediated by PKC or PKA and independent of protein synthesis. The change in the phosphorylation produced by 5 -HT of one protein (L55) may be mediated by PKA and dependent on protein synthesis. Finally, the change in phosphorylation of another set of proteins (SL30,L29, $L 35, L 54$, and $L 57$ ) appeared to be mediated through unknown second messenger systems, but the change in phosphorylation of these proteins appeared to require protein synthesis.

with 5-HT could play important roles in the induction or expression of long-term facilitation.

By what mechanism do different durations of 5-HT produce changes in phosphorylation of different proteins? The change in the phosphorylation of proteins produced by the short duration treatment with 5 -HT was transient (Fig. $2 A$ ). One possible mechanism for this transient phosphorylation may be that 5-HT sequentially activates phosphatases and kinases in sensory neurons. For example, activation of a phosphatase by 5-HT would occur after the activation of a kinase in the case of the proteins whose phosphorylation was increased by 2 min treatments with 5-HT. The reverse sequence of events may occur in the case of the proteins whose phosphorylation was initially decreased by 5-HT. In the Aplysia nervous system, several phosphatases have 
been identified and some evidence suggests that phosphatases may play roles in mediating some cellular effects of 5-HT (Critz et al., 1991; Ichinose and Byrne, 1991; Endo et al., 1992; Wilson and Kaczmarek, 1993). Alternatively, other mechanisms for the transient phosphorylation produced by 5 -HT treatments could involve regulation of the turnover rate or the transport of these phosphoproteins.

The phosphorylation of another set of proteins required long durations of treatments with 5-HT (Figs. $2 B, C, 3 A$ ). Long but not short treatments with 5-HT could affect phosphorylation of new proteins through any number of mechanisms. One possibility is that different kinases are activated in a cascade fashion with increasing durations of 5-HT (Ahn et al., 1991). In addition, second messengers or activated kinases could accumulate in different regions of the cell in response to different durations of 5-HT treatments and, thus, affect the phosphorylation of different populations of proteins (Barsony and Marx, 1990; Scott and Carr, 1992). Indeed, in Aplysia, regulatory subunits of PKA exhibit discrete patterns of subcellular localization (Cheley et al., 1994). Also, other studies indicate that the catalytic subunit of PKA translocates into the nucleus only after a prolonged (greater than $1 \mathrm{hr}$ ) exposure of the cell to 5-HT (Bacskai et al., 1993).

$\Lambda$ nother possible mechanism to account for the differential effects of treatments with 5-HT could be that the effects of the longer duration treatments with 5-HT involved changes in protein synthesis. The changes in the phosphorylation of six proteins produced by $1.5 \mathrm{hr}$ treatments with 5 -HT were blocked by anisomycin (Fig. $3 A$ ). These results suggest that changes in the phosphorylation of these proteins depend in some way on the synthesis of proteins (Fig. $3 B$ ). Since anisomycin blocks the induction of facilitation as well as related changes in cellular events produced by 5-HT, the phosphorylation of the proteins that were affected by anisomycin could be critical for the induction of long-term facilitation (Montarolo et al., 1986; Sweatt and Kandel, 1989; Bergold et al., 1990; Bailey et al., 1992). There are two possible ways protein synthesis could be involved in the phosphorylation changes produced by 5 -HT. First, the increase in the phosphorylation of proteins in a 2-D gel could be due to an increase in the synthesis of proteins. However, treatments with 5-HT did not appear to affect the synthesis of the proteins whose phosphorylation was affected by 5-HT (Noel et al., 1991). Second, protein synthesis may be indirectly involved in changing the phosphorylation of proteins. For example, the change in phosphorylation produced by $1.5 \mathrm{hr}$ treatments with 5-HT could be mediated through changes in the synthesis of proteins such as protein kinases, phosphatases, or phosphatase inhibitors, which then lead to changes in protein phosphorylation. In this regard, protein synthesis-dependent alterations of kinases produced by 5-HT have been observed in Aplysia nervous tissue (Bergold et al., 1990; Sossin and Schwartz, 1993).

The changes in the phosphorylation of four proteins (L15, L22, L23, and L33) produced by 5-HT did not appear to depend on the synthesis of proteins (Table 3 , Fig. $3 A, B$ ). This result does not rule out the possibility that the phosphorylation of these proteins is important in long-term facilitation. The change in the phosphorylation of these proteins could precede the induction step that is dependent on protein synthesis and still be involved in the induction of long-term facilitation.

The change in the phosphorylation of five proteins produced by $1.5 \mathrm{hr}$ treatments with 5 -HT was mimicked by the application of CPT-cAMP for $1.5 \mathrm{hr}$ (Fig. 3A). Anisomycin only blocked the effect of 5-HT on one (L55) of these proteins (Fig. 3B). Previous studies have shown that treatments that stimulate the production of cAMP or activate PKA mimic the effects of 5-HT on sensory neurons that are associated with long-term facilitation (Scholz and Byrne, 1988; Schacher et al., 1988, 1993; Nazif et al., 1991). Therefore, the phosphorylation of these proteins could play important roles in the induction of long-term facilitation. Since protein synthesis is required with activation of PKA to produce long-term facilitation, protein L55 has the characteristics of a protein that might play a key role in generating long-term facilitation (Fig. $3 B$ ).

The changes in the phosphorylation of four of the proteins affected by treatments with CPT-cAMP were also mimicked by treatments with PDAc, which by themselves do not produce long-term facilitation (Schacher et al., 1988) (Fig. 3B). There are several possible mechanisms by which the phosphorylation of proteins can be affected by both CPT-cAMP and PDAc treatments. First, these proteins may contain different sites for PKA and PKC. Thus, if the phosphorylation of these proteins play critical roles in induction of long-term facilitation, only the phosphorylation at the PKA site might control the function of this protein. There are many examples of proteins, which are phosphorylated at different sites by different kinases, whose functions are regulated only by one kinase (reviewed in Roach et al., 1991). A second possibility is that the protein is only phosphorylated by one kinase, which is activated by the other kinase (reviewed in Nishizuka, 1986). We have, thus far, only shown that analogs of second messengers can mimic some of the effects of 5-HT. It remains to be established whether activation of spccific kinases arc involved in mediating these effects of second messengers or, indeed, the effects produced by $5-\mathrm{HT}$.

The phosphorylation of five proteins affected by $1.5 \mathrm{hr}$ treatments with 5-HT did not appear to be mimicked by treatments with either CPT-cAMP or PDAc (Fig. $3 A, B$ ). This observation suggests that some effects of 5-HT may require either the combined activation of PKA and PKC or activation of isoforms of PKA or PKC that are not activated effectively by treatments with CPT-cAMP or PDAc. Alternatively, the changes produced by $1.5 \mathrm{hr}$ treatments with $5-\mathrm{HT}$ that were not mimicked by CPT-cAMP or PDAc could be mediated by the activation of another kinase, such as $\mathrm{Ca}^{2+} /$ calmodulin-dependent protein $\mathrm{ki}$ nase (CaMK). Serotonin causes translocation of a subunit of CaMK from cell membranes to the cytosol and possibly activation of CaMK (Saitoh and Schwartz, 1983, 1985). Therefore, activation of CaMK could mediate the changes in the phosphorylation of the proteins affected by 5-HT treatments but not by CPT-cAMP or PDAc treatments. Some recent evidence suggests a role for CaMK in 5-HT-induced synaptic facilitation in Aplysia (Nakanishi et al., 1994).

In summary, we have shown that different durations of treatments with 5-HT affected the phosphorylation of different proteins. The proteins whose phosphorylation was affected by 2 min treatments with 5-HT could be involved in short-term facilitation or in early stages of a cascade of events preceding the induction of long-term facilitation. The proteins whose phosphorylation was affected by $1.5 \mathrm{hr}$ treatments with 5-HT could be involved in long-term facilitation. A model summarizing the possible mechanisms involved in the phosphorylation changes produced by $1.5 \mathrm{hr}$ treatments with $5-\mathrm{HT}$ is presented in Figure $3 B$. Only some of the effects of $1.5 \mathrm{hr}$ treatments with 5 -HT on the phosphorylation of proteins were mimicked by 
CPT-cAMP and/or PD $\Lambda$ c. In addition, some of the effects of $1.5 \mathrm{hr}$ treatments with 5-HT on the phosphorylation of proteins appeared to require the synthesis of proteins. Interestingly, the effect of 5-HT on one of these proteins, L55, was mimicked by CPT-cAMP. Thus, L55 is a good candidate for a protein that might play a key role in long-term facilitation. The elucidation of the cellular functions of the proteins characterized in this study and their specific roles in facilitation await the identification of these proteins. We have begun to identify these phosphoproteins by obtaining their amino acid sequences using microsequencing techniques (Homayouni et al., 1994a,b). Phosphoproteins S6 and S31 are similar to an intermediate filament protein and a vertebrate heterogeneous nuclear ribonucleoprotein, respectively. In addition, protein appears to be a calmodulin-like $\mathrm{Ca}^{2+}$ binding protein, respectively.

\section{References}

Ahn NG, Weiel JE, Chan CP, Krebs EG (1990) Identification of multiple epidermal growth factor-stimulated protein serine/threonine kinases from Swiss 3T3 cells. J Biol Chem 265:1 1487-1 1494.

Ahn NG, Seger R, Bratlien RL, Diltz CD, Tonks NK, Krebs EG (1991) Multiple components in an epidermal growth factor-stimulated protein kinase cascade. J Biol Chem 266:4220-4227.

Azhderian EM, Kaczmarek LK (1991) Phosphorylation of membraneassociated proteins by phorbol esters in isolated bag cell neurons of Aplysia. J Neurobiol 22:105-115.

Bacskai BJ, Hochner B, Mahaut-Smith M, Adams SR, Kaang BK, Kandel ER, Tsien RY (1993) Spatially resolved dynamics of cAMP and protein kinase A subunits in Aplysia sensory neurons. Science 260: 222-226.

Bailey CH, Chen M, Keller F, Kandel ER (1992) Serotonin-mediated endocytosis of apCAM: an early step of learning-related synaptic growth in Aplysia. Science 256:645-649.

Barsony J, Marx S.J (1990) Immunocytology on microwave-fixed cells reveals rapid and agonist-specific changes in subcellular accumulation patterns for cAMP or cGMP. Proc Natl Acad Sci USA 87:1188-1 192.

Barzilai A, Kennedy TE, Sweatt JD, Kandel ER (1989) 5-HT modulates protein synthesis and the expression of specific proteins during long-term facilitation in Aplysia sensory neurons. Neuron 2:15771586 .

Baxter DA, Byrne JH (1989) Serotonergic modulation of two potassium currents in the pleural sensory neurons of Aplysia. J Neurophysiol 62:665-679.

Bergold PJ, Sweatt JD, Winicov I, Weiss KR, Kandel ER (1990) Protein synthesis during acquisition of long-term facilitation is needed for the persistent loss of regulatory subunits of the Aplysia cAMPdependent protein kinase. Proc Natl Acad Sci USA 87:3788-3791.

Bernier L, Castellucci VF, Kandel ER, Schwartz JH (1982) Facilitatory transmitter causes a selective and prolonged increase in adenosine $3^{\prime}$ : 5 -monophosphate in sensory neurons mediating the gill and siphon withdrawal reflex in Aplysia. J Neurosci 2:1682-1691.

Brunelli M, Castellucci VF, Kandel ER (1976) Synaptic facilitation and behavioral sensitization in Aplysia: possible role of serotonin and cyclic AMP. Science 194:1178-1181.

Byrne JH, Baxter DA, Buonomano DV, Cleary LJ, Eskin A, Goldsmith JR, McClendon E, Nazif FA, Noel F, Scholz KP (1991) Aspects of the neuronal and molecular bases of short- and long-term forms of nonassociative and associative learning in Aplysia. Ann NY Acad Sci 627:124-149.

Byrne JH, Zwartjes R, Homayouni R, Critz SD, Eskin A (1993) Roles of second messenger pathways in neuronal plasticity and in learning an memory: insights gained from Aplysia. Adv Second Messenger Phosphoprotein Res 27:1-62.

Carew TJ, Castellucci VF, Kandel ER (1971) An analysis of dishabituation and sensitization of the gill-withdrawal reflex in Aplysia. J Neurosci 2:79-98.

Castellucci VF, Kandel ER, Schwartz JH, Wilson FD, Nairn AC, Greengard P (1980) Intracellular injection of the catalytic subunit of cyclic AMP-dependent protein kinase simulates facilitation of transmitter release underlying behavioral sensitization in Aplysia. Proc Natl Acad Sci USA 77:7492-7496.
Castellucci VF, Nairn A, Greengard P, Schwartz JH, Kandel ER (1982) Inhibitor of adenosine $3^{\prime}: 5^{\prime}$-monophosphate-dependent protein kinase blocks presynaptic facilitation in Aplysia. $J$ Neurosci 2:16731681.

Cheley S, Panchal RG, Carr DW, Scott JD, Bayley H (1994) Type II regulatory subunits of cAMP-dependent protein kinase and their binding proteins in the nervous system of Aplysia californica. J Biol Chem 269:2911-2920.

Critz SD, Byrne JH (1992) Modulation of $I_{\mathrm{K} . \mathrm{Ca}}$ by phorbol ester mediated activation of PKC in pleural sensory neurons of Aplysia. $\mathrm{J}$ Neurophysiol 68(4):1079-1086.

Critz SD, Endo S, Shenolikar S, Byrne JH (1991) Protein phosphatase-1 inhibitors attenuate 5-HT modulated $\mathrm{K}^{+}$currents in Aplysia sensory neurons. Soc Neurosci Abstr 17:69.

Dash PK, Hochner B, Kandel ER (1990) Injection of the cAMPresponsive element into the nucleus of Aplysia sensory neurons blocks long-term facilitation. Nature 345:718-721.

Donaldson RW, Hagedorn CH, Cohen S (1991) Epidermal growth factor or okadaic acid stimulates phosphorylation of eukaryotic initiation factor 4F. J Biol Chem 266:3162-3166.

Emptage NJ, Carew TJ (1993) Long-term synaptic facilitation in the absence of short-term facilitation in Aplysia neurons. Science 262: 253-256.

Endo S, Shenolikar S, Eskin A, Zwartjes R, Byrne JH (1992) Characterization of neuronal protein phosphatases in Aplysia californica. J Neurochem 58:975-982.

Eskin A, Yeung SJ, Klass MR (1984) Requirement for protein synthesis in the regulation of a circadian rhythm by serotonin. Proc Natl Acad Sci USA 81:7637-7641

Eskin A, Garcia KS, Byrne JH (1989) Information storage in the nervous system of Aplysia: specific proteins affected by serotonin and cAMP. Proc Natl Acad Sci USA 86:2458-2462.

Frost WN, Castellucci VF, Hawkins RD, Kandel ER (1985) Monosynaptic connections made by the sensory neurons of the gill- and siphon-withdrawal reflex in Aplysia participate in the storage of longterm memory for sensitization. Proc Natl Acad Sci USA 82:82668269.

Ghirardi M, Braha O, Hochner B, Montarolo PG, Kandel ER, Dale N (1992) Roles of PKA and PKC in facilitation of evoked and spontaneous transmitter release at depressed and nondepressed synapses in Aplysia sensory neurons. Neuron 9:479-489.

Glanzman DL, Mackey SL, Hawkins RD, Dyke AM, Lloyd PE, Kandel ER (1989) Depletion of serotonin in the nervous system of Aplysia reduces the behavioral enhancement of gill withdrawal as well as the heterosynaptic facilitation produced by tail shock. J Neurosci 9:4200 4213.

Greenberg SM, Castellucci VF, Bayley H, Schwartz JH (1987) A molecular mechanism for long-term sensitization in Aplysia. Nature 329: $62-65$.

Hagiwara M, Alberts A, Brindle P, Meinkoth J, Feramisco J, Deng T, Karin M, Shenolikar S, Montminy M (1992) Transcriptional attenuation following cAMP induction requires PP-1-mediated dephosphorylation of CREB. Cell 70:105-113.

Hawkins RD, Kandel ER, Siegelbaum SA (1993) Learning to modulate transmitter release: themes and variations in synaptic plasticity. Annu Rev Neurosci 16:625-665.

Homayouni R, Nunez-Regueiro M, Cook R, Byrne JH, Eskin A (1994a) Serotonin affects the phosphorylation of intermediate filament protein and aldolase in Aplysia sensory neurons. J Neurochem, in press.

Homayouni R, Nunez-Regueiro M, Byrne JH, Eskin A (1994b) Identification of phosphoproteins that may be involved in learning and memory in Aplysia. Soc Neurosci Abstr 20: in press.

Ichinose M, Byrne JH (1991) Role of protein phosphatases in the modulation of neuronal membrane currents. Brain Res 549:146-150.

Kaang BK, Kandel ER, Grant SGN (1993) Activation of cAMP-responsive genes by stimuli that produce long-term facilitation in $A p l y$ sia sensory neurons. Neuron 10:427-435.

Kistler HB, Hawkins RD, Koester J, Steinbusch HWM, Kandel ER, Schwartz JH (1985) Distribution of serotonin-immunoreactive cell bodies and processes in the abdominal ganglion of mature Aplysia. $\mathrm{J}$ Neurosci 5:72-80.

Lemos JR, Novak-Hofer I, Levitan IB (1984) Synaptic stimulation alters protein phosphorylation in vivo in a single Aplysia neuron. Proc Natl Acad Sci USA 81:3233-3237.

Montarolo PG, Goelet P, Castellucci VF, Morgan J, Kandel ER, Schach- 
er $S$ (1986) A critical period of macromolecular synthesis in longterm heterosynaptic facilitation in Aplysia. Science 234:1249-1254.

Mooney RA, Anderson DL (1989) Phosphorylation of the insulin receptor in permeabilized adipocytes is coupled to a rapid dephosphorylation reaction. J Biol Chem 264:6850-6857.

Moreland S, Nishimura J, Van Breemen C, Ahn HY, Moreland RS (1992) Transient myosin phosphorylation at constant $\mathrm{Ca}^{2+}$ during agonist activation of permeabilized arteries. Am J Physiol 263:C540C544.

Nakanishi K, Zhang F, Baxter DA, Eskin A, Byrne JH (1994) $\mathrm{Ca}^{2+}$ calmodulin-dependent protein kinase II inhibitor, KN62, affects both basal synaptic strength and serotonin-induced facilitation of the sensorimotor synaptic connection in Aplysia. Soc Neurosci Abstr 20: in press.

Nazif FA, Byrne JH, Cleary LJ (1991) cAMP induces long-term morphological changes in sensory neurons of Aplysia. Brain Res 539:324327.

Nishizuka Y (1986) Studies and perspectives of protein kinase C. Science 233:305-312.

Noel F, Scholz KP, Eskin A, Byrne JH (1991) Common set of proteins in Aplysia sensory neurons affected by an in vitro analogue of longterm sensitization training, 5-HT and cAMP. Brain Res 568:67-75.

Noel F, Nunez-Regueiro M, Cook R, Byrne JH, Eskin A (1993) Longterm changes in synthesis of intermediate filament protein, actin and other proteins in pleural sensory neurons of Aplysia produced by an in vitro analogue of sensitization training. Mol Brain Res 19:203-210.

Ocorr KA, Byrne JH (1985) Membrane responses and changes in cAMP levels in Aplysia sensory neurons produced by serotonin, tryptamine, FMRFamide and small cardioactive peptide B (SCPB). Neurosci Lett 55:113-118.

Ocorr KA, Byrne JH (1986) Evidence for separate receptors that mediate parallel effects of serotonin and small cardioactive pcptide B (SCPB) on adenylate cyclase in Aplysia californica. Neurosci Lett 70: 283-288.

O'Farrell PH (1975) High resolution two-dimensional electrophoresis of proteins. J Biol Chem 250:4007-4021.

Pieroni JP, Byrne JH (1992) Differential effects of serotonin, FMRFamide, and small cardioactive peptide on multiple, distributed processes modulating sensorimotor synaptic transmission in Aplysia. J Neurosci 12:2633-2647.

Rayport SG, Schacher S (1986) Synaptic plasticity in vitro: cell culture of identified Aplysia neurons mediating short-term habituation and sensitization. J Neurosci 6:759-763.

Roach PJ (1991) Multisite and hierarchal protein phosphorylation. J Biol Chem 266:14139-14142.

Sacktor TC, Schwartz JH (1990) Sensitizing stimuli cause translocation of protein kinase C in Aplysia sensory neurons. Proc Natl Acad Sci USA 87:2036-2039.

Saitoh T, Schwartz JH (1983) Serotonin alters the subcellular distribution of a $\mathrm{Ca}^{2+} /$ calmodulin-binding protein in neurons of Aplysia. Proc Natl Acad Sci USA 80:6708-6712.

Saitoh T, Schwartz JH (1985) Phosphorylation-dependent subcellular translocation of a Ca ${ }^{+} /$calmodulin-dependent protein kinase produc- es an autonomous enzyme in Aplysia neurons. J Cell Biol 100:835842.

Sato C, Nishizawa K, Nakayama T, Ohtsuka K, Nakamura H, Kobayashi T, Inagaki M (1988) Rapid phosphorylation of MAP-2-related cytoplasmic and nuclear $\mathrm{Mr} 300,000$ protein by serine kinases after growth stimulation of quiescent cells. Exp Cell Res 175:136-147.

Schacher S, Castellucci VF, Kandel ER (1988) cAMP evokes longterm facilitation in Aplysia neurons that requires new protein synthesis. Science 240:1667-1669.

Schacher S, Kandel ER, Montarolo PG (1993) cAMP and arachidonic acid simulate long-term structural and functional changes produced by neurotransmitters in Aplysia sensory neurons. Neuron 10:1079 1088.

Scholz KP, Byrne JH (1988) Intracellular injection of cAMP induces a long-term reduction of neuronal $\mathrm{K}$ currents. Science 240:16641666.

Schwartz JH, Castellucci VF, Kandel ER (1971) Functioning of identified neurons and synapses in abdominal ganglion of Aplysia in absence of protein synthesis. J Neurophysiol 34:939-953.

Scott JD, Carr DW (1992) Subcellular localization of the type II cAMPdependent protein kinase. News Physiol Sci 7:143-148.

Sossin WS, Schwartz JH (1992) Selective activation of $\mathrm{Ca}^{+}$-activated PKCs in Aplysia neurons by 5-HT. J Neurosci 12:1160-1168.

Sossin WS, Schwartz JH (1993) Persistent activation of the $\mathrm{Ca}^{2+}$ activated PKC in Aplysia requires protein synthesis. Soc Neurosci Abstr 19:1065.

Sugita S, Goldsmith JR, Baxter DA, Byrne JH (1992) Involvement of protein kinase $\mathrm{C}$ in serotonin-induced spike broadening and synaptic facilitation in sensorimotor connections of Aplysia. J Neurophysiol 68:643-651.

Sweatt JD, Kandel ER (1989) Persistent and transcriptionally-dependent increase in protein phosphorylation in long-term facilitation of Aplysia sensory neurons. Nature 339:51-54.

Wahl MI, Olashaw NE, Nishibe S, Rhee SG, Pledger WJ, Carpenter G (1989) Platelet-derived growth factor induces rapid and sustained tyrosine phosphorylation of phospholipase $\mathrm{C}-\gamma$ in quiescent BALB/c 3 T3 cells. Mol Cell Biol 9:2934-2943.

Walters ET, Byrne JH, Carew TJ, Kandel ER (1983) Mechanoafferent neurons innervating tail of Aplysia. II. Modulation by sensitizing stimulation. J Neurophysiol 50:1543-1559.

Wilson GF, Kaczmarek LK (1993) Mode switching of a voltage-gated cation channel is mediated by a protein kinase A-regulated tyrosine phosphatase. Nature 366:433-438.

Yeung SJ, Eskin A (1987) Involvement of a specific protein in the regulation of a circadian rhythm in Aplysia eye. Proc Natl Acad Sci USA 84:279-283.

Zhang ZS, Fang B, Marshak DW, Byrne JH, Cleary LJ (1991) Serotonergic varicosities make synaptic contacts with pleural sensory neurons of Aplysia. J Comp Neurol 311:259-270.

Zwartjes RE, Eskin A (1990) Changes in protein phosphorylation in the eye of Aplysia associated with circadian rhythm regulation by serotonin. J Neurobiol 21:376-383. 